\title{
EASL-EASD-EASO Clinical Practice Guidelines for the management of non-alcoholic fatty liver disease
}

\author{
European Association for the Study of the Liver (EASL) - European Association for the \\ Study of Diabetes (EASD) • European Association for the Study of Obesity (EASO)
}

Published online: 7 April 2016

(C) Springer-Verlag Berlin Heidelberg 2016

$\begin{array}{ll}\text { Abbreviations } \\ \text { ALT } & \text { Alanine transaminase } \\ \text { BMI } & \text { Body mass index } \\ \text { CAP } & \text { Controlled attenuation parameter } \\ \text { CCR } & \text { Chemokine receptor } \\ \text { CK-18 } & \text { Cytokeratin-18 fragments } \\ \text { CKD } & \text { Chronic kidney disease } \\ \text { CT } & \text { Computed tomography } \\ \text { CVD } & \text { Cardiovascular disease } \\ \text { EASD } & \text { European Association for the Study of Diabetes } \\ \text { EASL } & \text { European Association for the Study of the Liver } \\ \text { EASO } & \text { European Association for the Study of Obesity } \\ \text { ELF } & \text { Enhanced liver fibrosis } \\ \text { F } & \text { Fibrosis stage } \\ \text { FIB-4 } & \text { Fibrosis } 4 \text { calculator } \\ \text { FLI } & \text { Fatty liver index } \\ \text { HbA } & \text { Glycosylated haemoglobin } \mathrm{A}_{1 \mathrm{c}} \\ \text { HCC } & \text { Hepatocellular carcinoma } \\ \text { HDL } & \text { High-density lipoprotein } \\ \text { HOMA-IR } & \text { Homeostasis model assessment of insulin resistance }\end{array}$

Contributors: Coordinator EASL: Giulio Marchesini; Panel members: Christopher P. Day, Jean-François Dufour, Ali Canbay, Valerio Nobili, Vlad Ratziu, Herbert Tilg; Coordinator EASD: Michael Roden; Panel members: Amalia Gastaldelli, Hannele Yki-Järvinen, Fritz Schick; Coordinator EASO: Roberto Vettor; Panel members: Gema Frühbeck, Lisbeth Mathus-Vliegen.

These Guidelines were developed by the EASL, EASD and the EASO, and are being published simultaneously in the Journal of Hepatology, Diabetologia and Obesity Facts.

Electronic supplementary material The online version of this article (doi:10.1007/s00125-016-3902-y) contains peer-reviewed but unedited supplementary material, which is available to authorised users.

European Association for the Study of the Liver (EASL) easloffice@easloffice.eu

1 EASL Office, 7 Rue Daubin, CH 1203 Geneva, Switzerland

$\begin{array}{ll}\text { IFG } & \text { Impaired fasting glucose } \\ \text { IR } & \text { Insulin resistance } \\ \text { LDL } & \text { Low-density lipoprotein } \\ \text { MetS } & \text { Metabolic syndrome } \\ \text { MRI } & \text { Magnetic resonance imaging } \\ \text { MRS } & \text { Magnetic resonance spectroscopy } \\ \text { NAFL } & \text { Non-alcoholic fatty liver } \\ \text { NAFLD } & \text { Non-alcoholic fatty liver disease } \\ \text { NAS } & \text { NAFLD Activity Score } \\ \text { NASH } & \text { Non-alcoholic steatohepatitis } \\ \text { NFS } & \text { NAFLD fibrosis score } \\ \text { NPV } & \text { Negative predictive value } \\ \text { OGTT } & \text { Oral glucose tolerance test } \\ \text { PNPLA3 } & \text { Patatin-like phospholipase domain containing 3 } \\ \text { PPAR } & \text { Peroxisome proliferator-activated receptor } \\ \text { PPV } & \text { Positive predictive value } \\ \text { PUFA } & \text { Polyunsaturated fatty acids } \\ \text { RCT } & \text { Randomised controlled trial } \\ \text { SAF } & \text { Steatosis, activity and fibrosis } \\ \text { T2DM } & \text { Type 2 diabetes mellitus } \\ \text { TM6SF2 } & \text { Transmembrane 6 superfamily 2 } \\ \text { UDCA } & \text { Ursodeoxycholic acid } \\ \text { US } & \text { Ultrasound }\end{array}$

\section{Introduction}

The Clinical Practice Guidelines propose recommendations for the diagnosis, treatment and follow-up of non-alcoholic fatty liver disease (NAFLD) patients and are the product of a joint effort by the European Association for the Study of the Liver (EASL), European Association for the Study of Diabetes (EASD) and European Association for the Study of Obesity (EASO). They update a position statement based on the 2009 EASL Special Conference [1]. 
The data have been retrieved by an extensive PubMed search up to April 2015. The final statements are graded according to the level of evidence and strength of recommendation, which are adjustable to local regulations and/or team capacities (Table 1) [2]. In particular, screening for NAFLD in the population at risk should be in the context of the available resources, considering the burden for the national healthcare systems and the currently limited effective treatments. The document is intended both for practical use and for advancing the research and knowledge of NAFLD in adults, with specific reference to paediatric NAFLD whenever necessary. The final purpose is to improve patient care and awareness of the importance of NAFLD, and to assist stakeholders in the decisionmaking process by providing evidence-based data, which also takes into consideration the burden of clinical management for the healthcare system.

\section{Definition}

NAFLD is characterised by excessive hepatic fat accumulation, associated with insulin resistance (IR), and defined by the presence of steatosis in $>5 \%$ of hepatocytes according to histological analysis or by a proton density fat fraction (PDFF, providing a rough estimation of the volume fraction of fatty material in the liver) $>5.6 \%$ assessed by proton magnetic resonance spectroscopy ( ${ }^{1} \mathrm{H}$-MRS) or quantitative fat/water selective magnetic resonance imaging (MRI). NAFLD includes two pathologically distinct conditions with different prognoses: non-alcoholic fatty liver (NAFL) and non-alcoholic steatohepatitis (NASH); the latter covers a wide spectrum of disease severity, including fibrosis, cirrhosis and hepatocellular carcinoma (HCC) (Table 2).

The diagnosis of NAFLD requires the exclusion of both secondary causes and a daily alcohol consumption $\geq 30 \mathrm{~g}$ for men and $\geq 20 \mathrm{~g}$ for women [1]. Alcohol consumption above these limits indicates alcoholic liver disease. The relationship between alcohol and liver injury depends on several cofactors (type of alcoholic beverage, drinking patterns, duration of exposure, individual/ genetic susceptibility), rendering simple quantitative thresholds at least partly arbitrary. Specifically, patients consuming moderate amounts of alcohol may be still predisposed to NAFLD if they have metabolic risk factors. Of note, the overall impact of metabolic risk factors on the occurrence of steatosis appears to be higher than that of alcohol in these patients [3]. The definitive diagnosis of NASH requires a liver biopsy.

\section{Recommendations}

- Patients with IR and/or metabolic risk factors (i.e. obesity or metabolic syndrome [MetS]) should undergo diagnostic procedures for the diagnosis of NAFLD, which relies on the demonstration of excessive liver fat (A1)

- Individuals with steatosis should be screened for secondary causes of NAFLD, including a careful assessment of alcohol intake. The interaction between moderate amounts of alcohol and metabolic factors in fatty liver should always be considered (A1)

- Other chronic liver diseases that may coexist with NAFLD should be identified as this might result in more severe liver injury (B1)

\section{Prevalence and incidence}

NAFLD is the most common liver disorder in Western countries, affecting $17-46 \%$ of adults, with differences according to the diagnostic method, age, sex and ethnicity [4]. It parallels the prevalence of MetS and its components, which also increases the risk of more advanced disease, both in adults and in children. NAFLD is also present in $7 \%$ of normal-weight (lean) persons [5], more frequently in females, at a younger age and with normal liver enzymes. Their liver disease may nonetheless be progressive [6].

NAFLD incidence has rarely been measured. It was 20-86/1000 person-years based on elevated liver enzymes and/or on ultrasound (US), and 34/1000 per year by ${ }^{1} \mathrm{H}-\mathrm{MRS}$ [7].

The need for NAFLD screening in the community has been questioned given the high direct and indirect costs of testing, the low predictive value of non-invasive tests, the risks of liver biopsy and the lack of effective treatments [8]. However, the progressive form of NAFLD (i.e. NASH), particularly when associated with advanced fibrosis, should be identified in patients at risk (age $>50$ years, type 2 diabetes mellitus [T2DM] or MetS), because of its prognostic implications. Validated cost-utility studies on extensive screening programmes are eagerly awaited. Similarly, although familial clustering occurs, family screening is not generally advisable, with the exception of cases with defined inherited diseases (e.g. lysosomal acid lipase deficiency). 


\section{Recommendations}

- All individuals with steatosis should be screened for features of MetS, independent of liver enzymes. All individuals with persistently abnormal liver enzymes should be screened for NAFLD, because NAFLD is the main reason for unexpectedly elevated liver enzymes (A1)

- In subjects with obesity or MetS, screening for NAFLD by liver enzymes and/or ultrasound should be part of routine work-up. In high-risk individuals (age $>50$ years, $\mathrm{T} 2 \mathrm{D}, \mathrm{MetS}$ ) case finding of advanced disease (i.e. NASH with fibrosis) is advisable (A2)

\section{Pathogenesis: lifestyle and genes}

A high-calorie diet, excess (saturated) fats, refined carbohydrates, sugar-sweetened beverages, a high fructose intake and a Western diet [9] have all been associated with weight gain and obesity, and more recently with NAFLD. High fructose consumption may increase the risk of NASH and advanced fibrosis, although the association may be confounded by excess calorie intake or by unhealthy lifestyles and sedentary behaviour [10], which are more common in NAFLD [11].

\section{Recommendations}

- Unhealthy lifestyles play a role in the development and progression of NAFLD. The assessment of dietary and physical activity habits is part of comprehensive NAFLD screening (A1)

Several genetic modifiers of NAFLD have been identified [12], but a minority have been robustly validated (see electronic supplementary material [ESM] 1 Table 1]). The best-characterised genetic association is with PNPLA3, initially identified from genome-wide association studies and confirmed in multiple cohorts and ethnicities as a modifier of NAFLD severity across the entire histological spectrum [13, 14]. Recently, the TM6SF 2 gene has been reported as another disease modifier $[15,16]$ and may have clinical utility assisting risk stratification for liver-related vs cardiovascular morbidity.

The PNPLA3 rs738409 variant also confers susceptibility and affects the histological pattern of NAFLD and fibrosis in obese children and adolescents [17]. A NASH risk score based on four polymorphisms has been validated in obese children with increased liver enzymes [18].

\section{Recommendations}

- Carriers of the PNPLA3 I148M and the TM6SF2 E167K variants have a higher liver fat content and increased risk of NASH. NAFLD due to these variants is not systematically associated with features of insulin resistance. Genotyping may be considered in selected patients and clinical studies but is not recommended routinely (B2)

\section{Liver biopsy}

Liver biopsy is essential for the diagnosis of NASH and is the only procedure that reliably differentiates NAFL from NASH, despite limitations due to sampling variability [19].

NAFL encompasses: a) steatosis alone, b) steatosis with lobular or portal inflammation, without ballooning, and c) steatosis with ballooning but without inflammation [20]. The diagnosis of NASH requires the joint presence of steatosis, ballooning and lobular inflammation [20-22]. Other histological features can be seen in NASH, but are not necessary for the diagnosis: portal inflammation, polymorphonuclear infiltrates, Mallory-Denk bodies, apoptotic bodies, clear vacuolated nuclei, microvacuolar steatosis and megamitochondria. Perisinusoidal fibrosis is also frequent, but not part of the diagnostic criteria; the term 'borderline' NASH is confusing, unnecessary and should be abandoned. The prospectively designed FLIP algorithm increases observer agreement and precisely defines the grading of ballooning [22]. 'Burned-out NASH' describes regression of advanced disease (steatosis, inflammation or ballooning) in patients exposed to metabolic risk factors.

The NAFLD Activity Score (NAS) scoring system should not be used for the diagnosis of NASH but rather for the evaluation of disease severity, once the diagnosis has been established by the overall pathological assessment. Although NAS is correlated with aminotransferase and homeostasis model assessment of insulin resistance (HOMA-IR) [23], they have a low prognostic value [24]. The steatosis, activity and fibrosis (SAF) score [22] is an alternative with good reproducibility and provides a more accurate and comprehensive description. Fibrosis staging relies on the Kleiner classification [21] (used in a simplified pattern in SAF) [22].

In children, NASH displays many of the features observed in adults, even though the distribution of lesions may be different. Portal inflammation is a frequent feature, but can also be seen in adults with more severe disease [25]. Hepatocellular ballooning and Mallory-Denk bodies are only sporadically observed in paediatric NASH, and portal-based chronic inflammation is predominant [21]. Based on the distinctive histological pattern, a specific histological score (Paediatric NAFLD Histological Score - PNHS) has been validated for better classification of children with/without NASH [26]. 
Table 1 Evidence grade used for the EASL-EASD-EASO

Clinical Practice Guidelines on

NAFLD (adapted from the

GRADE system [8])

\begin{tabular}{|c|c|c|}
\hline Grading & Notes & Symbol \\
\hline \multicolumn{3}{|l|}{ Grading of evidence } \\
\hline High quality & $\begin{array}{l}\text { Further research is very unlikely to change } \\
\text { our confidence in the estimate effect }\end{array}$ & A \\
\hline Moderate quality & $\begin{array}{l}\text { Further research is likely to have an important } \\
\text { impact on our confidence in the estimate of } \\
\text { effect and may change the estimate effect }\end{array}$ & $\mathrm{B}$ \\
\hline Low or very low quality & $\begin{array}{l}\text { Further research is very likely to have an } \\
\text { important impact on our confidence in } \\
\text { the estimate of effect and may change } \\
\text { the estimate effect. Any estimate of effect } \\
\text { is uncertain }\end{array}$ & $\mathrm{C}$ \\
\hline \multicolumn{3}{|l|}{ Grading of recommendations } \\
\hline $\begin{array}{l}\text { Strong recommendation } \\
\text { warranted }\end{array}$ & $\begin{array}{l}\text { Factors influencing the strength of the } \\
\text { recommendation included the quality } \\
\text { of the evidence, presumed patient-important } \\
\text { outcomes, and cost }\end{array}$ & 1 \\
\hline \multirow[t]{2}{*}{ Weaker recommendation } & $\begin{array}{l}\text { Variability in preferences and values, or more } \\
\text { uncertainty: more likely a weak } \\
\text { recommendation is warranted }\end{array}$ & 2 \\
\hline & $\begin{array}{l}\text { Recommendation is made with less certainty; } \\
\text { higher cost or resource consumption }\end{array}$ & \\
\hline
\end{tabular}

\section{Non-invasive assessment}

Non-invasive markers should aim to: (i) in primary care settings, identify the risk of NAFLD among individuals with increased metabolic risk; (ii) in secondary and tertiary care settings, identify those with worse prognosis, e.g. severe NASH; (iii) monitor disease progression; (iv) predict response to therapeutic interventions. Achieving these objectives could reduce the need for liver biopsy.

Table 2 The spectrum of NAFLD and concurrent diseases

\begin{tabular}{|c|c|c|}
\hline Disease & Subclassification & Most common concurrent diseases \\
\hline NAFLD $^{\mathrm{a}}$ & $\begin{array}{l}\text { NAFL } \\
\qquad \text { Pure steatosis } \\
\text { • Steatosis and mild lobular inflammation } \\
\text { NASH } \\
\quad \text { • Early NASH: no or mild (F0-F1) fibrosis } \\
\text { • Fibrotic NASH: significant }(\geq \mathrm{F} 2) \text { or advanced } \\
\quad(\geq \mathrm{F} 3 \text {, bridging) fibrosis } \\
\text { • NASH-cirrhosis (F4) } \\
\text { Hepatocellular carcinoma }^{\mathrm{c}}\end{array}$ & $\begin{array}{l}\text { AFLD-Alcoholic fatty liver disease } \\
\text { Drug-induced fatty liver disease }{ }^{\mathrm{b}} \\
\text { Hepatitis C virus (HCV)-associated fatty liver } \\
{\text { (genotype } 3)^{\mathrm{b}}} \\
\text { Others } \\
\text { - Haemochromatosis } \\
\text { - Autoimmune hepatitis } \\
\text { - Coeliac disease } \\
\text { - Wilson's disease } \\
\text { - A/hypo-betalipoproteinaemia, lipoatrophy } \\
\text { - Hypopituitarism, hypothyroidism } \\
\text { - Starvation, parenteral nutrition } \\
\text { - Inborn errors of metabolism (Wolman disease } \\
\text { [lysosomal acid lipase deficiency]) }\end{array}$ \\
\hline
\end{tabular}

${ }^{a}$ Also called Primary NAFLD and associated with metabolic risk factors/components of Metabolic Syndrome:

1. Waist circumference $\geq 94 / \geq 80 \mathrm{~cm}$ for Europid men/women

2. Arterial pressure $\geq 130 / 85 \mathrm{mmHg}$ or treated for hypertension

3. Fasting glucose $\geq 100 \mathrm{mg} / \mathrm{dl}(5.6 \mathrm{mmol} / \mathrm{l})$ or treated for T2DM

4. Serum triacylglycerol $>150 \mathrm{mg} / \mathrm{dl}(>1.7 \mathrm{mmol} / \mathrm{l})$

5. HDL-cholesterol $<40 / 50 \mathrm{mg} / \mathrm{dl}$ for men/women $(<1.0 /<1.3 \mathrm{mmol} / \mathrm{l})$

${ }^{\mathrm{b}}$ Also called secondary NAFLD. Note that primary and secondary NAFLD may coexist in individual patients. Also NAFLD and AFLD may coexist in subjects with metabolic risk factors and drinking habits above safe limits.

${ }^{\mathrm{c}}$ Can occur in the absence of cirrhosis and histological evidence of NASH, but with metabolic risk factors suggestive of 'burned-out' NASH 


\section{Steatosis}

Rationale Steatosis should be documented whenever NAFLD is suspected as the primary disease or as a coexisting condition. It also predicts future diabetes mellitus, cardiovascular events and arterial hypertension. In clinical practice, quantification of fat content is not of interest, except as a surrogate of treatment efficacy, and is therefore not generally recommended.

In individual patients, especially in tertiary care centres, steatosis should be identified by imaging, preferably US, because it is more widely available and cheaper than the gold standard, MRI (ESM 1 Table 2). US has limited sensitivity and does not reliably detect steatosis when $<20 \%[27,28]$ or in individuals with high body mass index (BMI) $\left(>40 \mathrm{~kg} / \mathrm{m}^{2}\right)$ [29]. Despite observer dependency, US (or computed tomography [CT] or MRI) robustly diagnoses moderate and severe steatosis and provides additional hepatobiliary information, hence it should be performed as a first-line diagnostic test. However, for larger scale screening studies, serum biomarkers are preferred, as availability and cost of imaging substantially impact feasibility (ESM 1 Table 3). The best-validated steatosis scores are the fatty liver index (FLI), the SteatoTest ${ }^{\circledR}$ and the NAFLD liver fat score; they have all been externally validated in the general population or in grade 3 obese persons and variably predict metabolic, hepatic and cardiovascular outcomes/mortality. These scores are associated with IR and reliably predict the presence, not the severity, of steatosis [30]. Another imaging technique, the controlled attenuation parameter (CAP) can diagnose steatosis, but has a limited ability to discriminate histological grades and has never been compared with ${ }^{1} \mathrm{H}$-MRS-measured steatosis. Also, the data from studies comparing CAP with US are inconclusive. Thus more data are needed to define the role of CAP.

\section{Recommendations}

- US is the preferred first-line diagnostic procedure for imaging of NAFLD, as it provides additional diagnostic information (A1)

- Whenever imaging tools are not available or feasible (e.g. large epidemiological studies), serum biomarkers and scores are an acceptable alternative for the diagnosis of steatosis (B2)

- A quantitative estimation of liver fat can only be obtained by ${ }^{1} \mathrm{H}-\mathrm{MRS}$. This technique is of value in clinical trials and experimental studies, but is expensive and not recommended in the clinical setting (A1)

\section{Steatohepatitis, NASH}

Rationale The diagnosis of NASH provides important prognostic information and indicates an increased risk of fibrosis progression, cirrhosis and possibly hepatic comorbidities (HCC). It may also prompt a closer follow-up and possibly a greater need for more intensive therapy.

Clinical, biochemical or imaging measures cannot distinguish NASH from steatosis [31, 32]. Cytokeratin-18 fragments (CK-18), which are generated during cell death (M65 fragments) or apoptosis (M30 fragments), have modest accuracy for the diagnosis of NASH $(66 \%$ sensitivity, $82 \%$ specificity) [33, 34]. CK-18 changes parallel histological improvement but do not perform better than alanine transaminase (ALT) in identifying histological responders [35]. To date, non-invasive tests are not validated for the diagnosis of NASH.

\section{Recommendations}

- NASH has to be diagnosed by a liver biopsy showing steatosis, hepatocyte ballooning and lobular inflammation (A1)

\section{Fibrosis}

Rationale Fibrosis is the most important prognostic factor in NAFLD and is correlated with liver-related outcomes and mortality [24]. The presence of advanced fibrosis identifies patients in need of in-depth hepatological investigation, including, on a case-by-case basis, confirmatory biopsy and intensive therapies. Monitoring of fibrosis progression is also necessary at variable time intervals.

Many serum markers have shown acceptable diagnostic accuracy as defined by an area under the receiver operating characteristic curve (AUROC) $>0.8$ (ESM 1 Table 3) [32]. NAFLD fibrosis score (NFS) and fibrosis 4 calculator (FIB-4) have been externally validated in ethnically different NAFLD populations, with consistent results. NFS, FIB-4, Enhanced Liver Fibrosis (ELF) and FibroTest ${ }^{\circledR}$ predict overall mortality, cardiovascular mortality and liver-related mortality. NFS predicts incident diabetes, and changes in NFS are associated with mortality. The tests perform best at distinguishing advanced $(\geq F 3)$ vs non-advanced fibrosis but not significant $(\geq F 2)$ or any ( $\geq$ F1) fibrosis vs no fibrosis [36]. Importantly, the negative predictive values (NPVs) for excluding advanced fibrosis are higher than the corresponding positive predictive values (PPVs) [36, 37]; therefore, non-invasive tests may be confidently used for first-line risk stratification to 
exclude severe disease. However, predictive values depend on prevalence rates and most of these studies have been conducted in tertiary centres where the pre-test probability of advanced fibrosis is higher than in the community.

Among imaging techniques, transient elastography performs better for cirrhosis (F4) than for advanced fibrosis (F3). Elastography has a higher rate of false-positive than false-negative results and higher NPV than PPV [38], hence the ability to diagnose bridging fibrosis or cirrhosis is insufficient for clinical decision-making. The main shortcoming of transient elastography is unreliable results in the presence of high BMI and/or thoracic fold thickness. In a large, unselected European series, up to $20 \%$ of examinations had unreliable results [39], mainly in obese NAFLD [38]. The XL probe should be used in these patients to reduce the failure rate, which remains high (35\%) [40].

There is no consensus on thresholds or strategies for use in clinical practice when trying to avoid liver biopsy [32]. Some data suggest that the combination of elastography and serum markers performs better than either method alone [41]. Importantly, longitudinal data correlating changes in histological severity and in non-invasive measurements are urgently needed.

\section{Recommendations}

- Biomarkers and scores of fibrosis, as well as transient elastography, are acceptable non-invasive procedures for the identification of cases at low risk of advanced fibrosis/cirrhosis (A2). The combination of biomarkers/scores and transient elastography might confer additional diagnostic accuracy and might save a number of diagnostic liver biopsies (B2)

- Monitoring of fibrosis progression in clinical practice may rely on a combination of biomarkers/scores and transient elastography, although this strategy requires validation (C2)

- The identification of advanced fibrosis or cirrhosis by serum biomarkers/scores and/or elastography is less accurate and needs to be confirmed by liver biopsy, according to the clinical context (B2)

- In selected patients at high risk of liver disease progression, monitoring should include a repeat liver biopsy after at least 5-year follow-up (C2)

\section{Non-invasive testing in paediatric NAFLD}

The position paper by the European Society for Paediatric Gastroenterology Hepatology and Nutrition (ESPGHAN)
Hepatology Committee has recently delineated diagnostic criteria for paediatric NAFLD [42]. In obese children, NAFLD should always be suspected; elevated aminotransferase levels and liver hyperechogenicity deserve further evaluation and the exclusion of other causes of liver disease. Due to the poor sensitivity of these tests in overweight/obese children, non-invasive markers and imaging techniques are the first diagnostic step [43].

\section{Recommendations}

- In children, predictors of fibrosis, including elastometry, acoustic radiation force impulse (ARFI) imaging and serum biomarkers might help reduce the number of biopsies (B2)

\section{Common metabolic disorders related to NAFLD}

NAFLD is tightly associated with IR not only in the liver, but also in muscle and adipose tissues [44], and also with MetS, defined as the cluster of any three of the following five features associated with IR: impaired fasting glucose (IFG) or T2DM, hypertriglyceridaemia, low high-density lipoprotein (HDL)-cholesterol (genderadjusted), increased waist circumference (ethnicity adjusted) and high blood pressure [45]. As all components of MetS correlate with liver fat content, independently of BMI, the presence of MetS in any given patient should lead to an evaluation of the risk of NAFLD, and vice versa the presence of NAFLD should lead to an assessment of all components of MetS.

Hepatic triacylglycerol accumulation is accompanied by abnormal hepatic energy metabolism [46] and impaired insulin-mediated suppression of hepatic glucose and very low-density lipoprotein production [47], leading to hyperglycaemia, hypertriglyceridaemia and hyperinsulinaemia. In non-diabetic persons, the product of fasting glucose (in $\mathrm{mmol} / \mathrm{l}$ ) and insulin (in $\mathrm{mU} / \mathrm{ml}$ ), divided by 22.5 (HOMA-IR) can serve as surrogate for IR [48], and is therefore an acceptable alternative to more expensive and time-consuming dynamic testing. Liver disease progression has been associated with persistence or worsening of metabolic abnormalities, including HOMA-IR $[49,50]$. However, the validity of HOMA-IR depends on the ability of insulin secretion to adapt to IR, questioning its suitability in overt diabetes. Moreover, the assays for insulin measurements vary widely, and there is no agreement on a threshold defining IR using HOMA-IR. 


\section{Recommendations}

- HOMA-IR provides a surrogate estimate of IR in persons without diabetes and can therefore be recommended provided proper reference values have been established (A1)

- HOMA-IR is of limited use for NAFLD diagnosis in patients with metabolic risk factors. It could confirm altered insulin sensitivity, thereby favouring a diagnosis of IR-associated NAFLD in cases of diagnostic uncertainty (e.g. US-defined steatosis with normal body weight) (B2)

- During follow-up, HOMA-IR might help identify patients at risk of NASH or fibrosis progression in selected cases. Improvement of HOMA-IR during weight loss may indicate metabolic improvement that could be beneficial for NAFLD (C2)

\section{Obesity}

BMI and waist circumference, a measure of visceral adiposity, are positively related to the presence of NAFLD [51] and predict advanced disease, particularly in the elderly [52]. A large proportion of patients with cryptogenic cirrhosis have a high prevalence of metabolic risk factors [53], suggesting that the majority of cases of cryptogenic cirrhosis are 'burnedout' NASH. Common comorbidities of obesity, such as T2DM, and sleep apnoea [54], polycystic ovary syndrome and other endocrine disorders (hypogonadism), further drive NAFLD prevalence and severity.

Importantly, patients with BMI $<30 \mathrm{~kg} / \mathrm{m}^{2}$ (or even $<25 \mathrm{~kg} / \mathrm{m}^{2}$ ) but with visceral fat accumulation or dysfunctional adipose tissue can exhibit NAFLD with/without abnormal liver enzymes [44, 55]. The currently used concept of 'metabolically healthy' obese individuals should be considered with caution, given that they may exhibit gene expression similar to those of metabolically altered obese patients, and may have altered liver tests and adverse health outcomes when longitudinally examined $[56,57]$.

\section{Recommendations}

- Follow-up is mandatory in obesity, which is the major phenotype and risk condition for NAFLD, driven by IR, and also increases the risk of advanced disease (A1)

- Most lean persons with NAFLD display IR and altered body fat distribution even though they have less severe metabolic disturbance than overweight NAFLD. Followup is nonetheless required because of possible disease progression (B2)

\section{Diabetes mellitus}

T2DM patients are insulin resistant, often obese, dyslipidaemic, display increased liver enzymes [58] and tend to accumulate hepatic fat independently of BMI [59, 60]. The prevalence of NAFLD is also higher in persons at risk of T2DM, defined as a glycosylated haemoglobin $\mathrm{A}_{1 \mathrm{c}}\left(\mathrm{HbA}_{1 \mathrm{c}}\right)$ of 5.7-6.4\% (38.8-46.4 mmol/mol), IFG (fasting glucose: $100-125 \mathrm{mg} / \mathrm{dl}$ [5.55-6.94 mmol/1]) and/or impaired glucose tolerance (IGT; glucose: 140-199 mg/dl [7.77-11.04 mmol/1] at $2 \mathrm{~h}$ of the standardised $75 \mathrm{~g}$ oral glucose tolerance test [OGTT]). Diabetes risk and T2DM closely associate with the severity of NAFLD, progression to NASH, advanced fibrosis and the development of $\operatorname{HCC}[4,61]$, independently of liver enzymes [6]. Conversely, USdefined NAFLD is associated with a 2-5-fold risk of developing T2DM after adjustment for several lifestyle and metabolic confounders [62]. The standardised $75 \mathrm{~g}$ OGTT should therefore be performed in persons with increased diabetes risk [63, 64].

Insulin treatment increases body fat, but it does not appear to promote or worsen NAFLD in diabetes [65, 66]. While acute insulin infusion dose-dependently increases liver fat content in T2DM [67], chronic insulin treatment improves adipose tissue IR and therefore reduces NEFA flux and hepatic fat content.

\section{Recommendations}

- In persons with NAFLD, screening for diabetes is mandatory, by fasting or random blood glucose or $\mathrm{HbA}_{1 \mathrm{c}}$ (A1) and, if available, by the standardised $75 \mathrm{~g}$ OGTT in high-risk groups (B1)

- In patients with T2DM, the presence of NAFLD should be looked for irrespective of liver enzyme levels, since T2DM patients are at high risk of disease progression (A2)

\section{Diagnostic algorithm and follow-up}

The incidental discovery of steatosis should lead to comprehensive evaluation of family and personal history of NAFLDassociated diseases and the exclusion of secondary causes of steatosis. Metabolic work-up has to include a careful assessment of all components of MetS [63]. Similarly, the presence of obesity/T2DM or the incidental finding of raised liver enzymes in patients with metabolic risk factors should prompt non-invasive screening to predict steatosis, NASH and fibrosis (Table 3). 
Table 3 Protocol for a comprehensive evaluation of suspected NAFLD patients

\begin{tabular}{ll}
\hline Level & Item \\
\hline Initial & 1. Alcohol intake: $<20 \mathrm{~g} /$ day (women), $<30 \mathrm{~g} /$ day (men) \\
2. Personal and family history of diabetes, hypertension and CVD \\
3. BMI, waist circumference, change in body weight \\
4. Hepatitis B/Hepatitis C virus infection \\
5. History of steatosis-associated drugs \\
6. Liver enzymes (aspartate and alanine transaminases [ $\gamma$-glutamyl-trans-peptidase]) \\
7. Fasting blood glucose, HbA ${ }_{1 \mathrm{c}}$, OGTT, (fasting insulin [HOMA-IR]) \\
8. Complete blood count \\
9. Serum total and HDL-cholesterol, triacylglycerol, uric acid \\
10. US (if suspected for raised liver enzymes) \\
1. Ferritin and transferrin saturation \\
2. Tests for coeliac and thyroid diseases, polycystic ovary syndrome \\
3. Tests for rare liver diseases (Wilson, autoimmune disease, $\alpha 1$-antitrypsin deficiency) \\
Extended $^{\mathrm{a}}$
\end{tabular}

${ }^{\text {a }}$ According to a priori probability or clinical evaluation
Surrogate markers of fibrosis (NFS, FIB-4, ELF or FibroTest) should be calculated for every NAFLD patient, in order to rule out significant fibrosis $(\geq F 2)$. If significant fibrosis cannot be ruled out, patients should be referred to a Liver Clinic for transient elastography; if significant fibrosis is confirmed, the final diagnosis should be made by liver biopsy (Fig. 1). All cases with diabetes or diabetes risk should be referred to a Diabetes Clinic for optimal management. Those at increased diabetes risk should be included in a structured lifestyle modification programme. Obesity should prompt the inclusion of the patient in a structured weight loss programme and/or referral to an obesity specialist. Finally, all cases should receive comprehensive cardiovascular disease (CVD) work-up.

The optimal follow-up of patients with NAFLD is as yet undetermined. Risk of progression of both the hepatic disease and the underlying metabolic conditions as well as the cost and workload for healthcare providers need to be considered. Monitoring should include routine biochemistry, assessment of comorbidities and non-invasive monitoring of fibrosis. NAFL patients without worsening of metabolic risk factors, should be monitored at 2-3-year intervals. Patients with NASH and/or fibrosis should be monitored annually, those with NASH cirrhosis at 6-month intervals. If indicated on a case-by-case basis, liver biopsy could be repeated after 5 years.

\section{Natural history and complications}

\section{Disease progression}

In general, NAFLD is a slowly progressive disease, both in adults and in children, but fibrosis rapidly progresses in $20 \%$ of cases [68]. The rate of progression corresponds to 1 fibrosis stage every 14 years in NAFL and every 7 years in NASH, and is doubled by arterial hypertension [68]. NASH is associated with an increased standardised mortality ratio compared

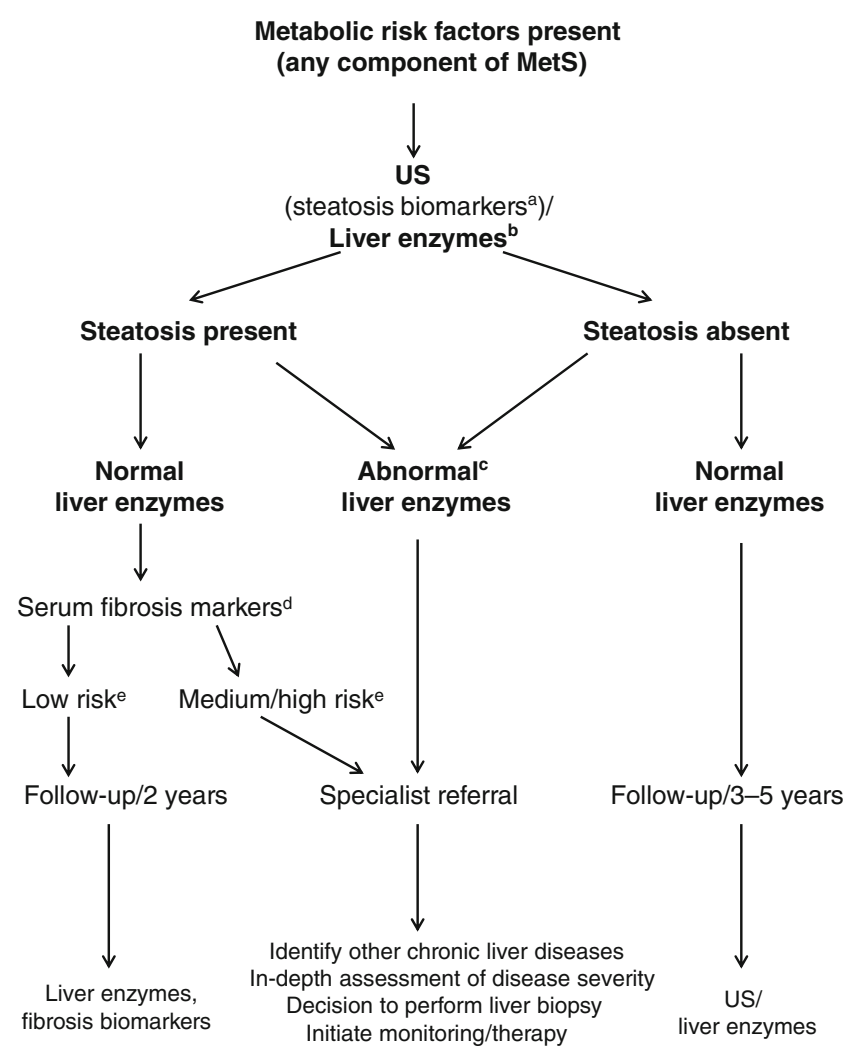

Fig. 1 Diagnostic flow-chart to assess and monitor disease severity in the presence of suspected NAFLD and metabolic risk factors. ${ }^{\text {a }}$ Steatosis biomarkers: Fatty Liver Index, SteatoTest, NAFLD Fat score (see Tables). ${ }^{\mathrm{b}}$ Liver tests: ALT AST, $\gamma$-glutamyltransferase (GGT). ${ }^{\mathrm{c}}$ Any increase in ALT, AST or $\gamma$-glutamyltransferase (GGT). ${ }^{\mathrm{d}}$ Serum fibrosis markers: NAFLD Fibrosis Score, FIB-4, Commercial tests (FibroTest, FibroMeter, ELF). ${ }^{\mathrm{e}}$ Low risk: indicative of no/mild fibrosis; Medium/ high risk: indicative of significant fibrosis or cirrhosis (see Tables) 
with the general population [69], and liver disease is the third most common cause of death after CVD and cancer. USdiagnosed NAFLD is not associated with increased mortality [70], presumably because progression to NASH and fibrosis is rare for steatosis alone $[49,50]$.

\section{Recommendations}

- NASH patients with fibrosis associated with hypertension should receive closer monitoring because of a higher risk of disease progression (B1)

Paediatric NAFLD is of concern because of the potential for severe liver-related complications later in life [8]. NASHrelated cirrhosis has been reported as early as 8 years of age [71].

\section{CVD}

The prevalence and incidence of CVD is higher in NAFLD than in matched controls and driven by the association between NAFLD and MetS components [72, 73] (ESM 1 Table 4). CVD is a more common cause of death than liver disease in NAFLD [73]. In most studies, biochemical markers of atherosclerosis (low HDL-cholesterol, high triacylglycerol) or inflammation (high-sensitive C-reactive protein [CRP]), and increased levels of procoagulant/prothrombotic factors are more common in NAFLD than in persons without steatosis [73]. Pre-atherogenic lesions such as increased carotid intima-media thickness; coronary artery, abdominal aortic and aortic valve calcifications; endothelial dysfunction and functional unresponsiveness of the artery wall are more prevalent in NAFLD and are, in some studies, correlated with histological severity. Other defects such as echocardiographic and ECG abnormalities and altered cardiac energy metabolism have also been demonstrated [74]. They are largely independent of traditional risk factors, duration of diabetes, glycaemic control, drug treatment and MetS components. In the general population, US-detected steatosis and its surrogate markers (e.g. FLI) are associated with a higher risk of CVD mortality in the long term [75], and the risk increases further in NASH and in advanced fibrosis [73].

The overall consensus is that CVD should be identified in NAFLD regardless of the presence of traditional risk factors. Conversely, NAFLD screening should be performed in persons at high CVD risk. An association between serum $\gamma$ glutamyltransferase (GGT) and CVD incidence has been prospectively established, although it is insufficient for devising follow-up protocols. Notably, CVD and metabolic risk factors are also reported in adolescents and children with NAFLD [76].

\section{Recommendations}

- Cardiovascular complications frequently dictate the outcome of NAFLD and screening of the cardiovascular system is mandatory in all persons, at least by detailed risk factor assessment (A1)

\section{HCC}

Large-scale epidemiological studies have repeatedly associated obesity and T2DM with the risk of HCC, and the occurrence of HCC has also been reported in NAFLD/cryptogenic cirrhosis. The cumulative incidence of NAFLD-associated HCC ( $>10$-fold higher in T2DM and obesity) varies according to study population (population-based, natural history vs clinic-based cohorts with/without fibrosis or cirrhosis) from $7.6 \%$ at 5 years in persons with advanced fibrosis or cirrhosis to only $0.25 \%$ in a larger series followed for 5.6 years [77].

At diagnosis, patients with NAFLD-associated HCC are older than those with non-NAFLD HCC, have more extrahepatic comorbidities, but a lower prevalence of cirrhosis (only two-thirds of cases) (ESM 1 Table 5). NAFLD-related HCC may, however, be diagnosed at more advanced stages, due to less systematic surveillance, and receive less treatment. Conflicting data are reported on survival. At present, NAFLD is the second leading indication for HCC-related transplantation in the USA [78].

The large number of NAFLD cases at risk of HCC makes systematic surveillance largely impracticable. The PNPLA3 rs738409 $\mathrm{C}>\mathrm{G}$ gene polymorphism has been associated with an increased HCC risk and might provide patient-risk stratification for tailored HCC surveillance in NAFLD, but it is not yet considered cost-effective (ESM 1 Table 1).

\section{Recommendations}

- Although NAFLD is a risk factor for HCC, which may also develop in the pre-cirrhotic stage, and the risk is further increased by the presence of the PNPLA3 rs738409 $\mathrm{C}>\mathrm{G}$ polymorphism, no recommendation can be currently made on the timing of surveillance and its cost-effectiveness (B1)

\section{Other extrahepatic disorders}

Chronic kidney disease (CKD) can be found in $20-50 \%$ of NAFLD patients, particularly in biopsy-proven 


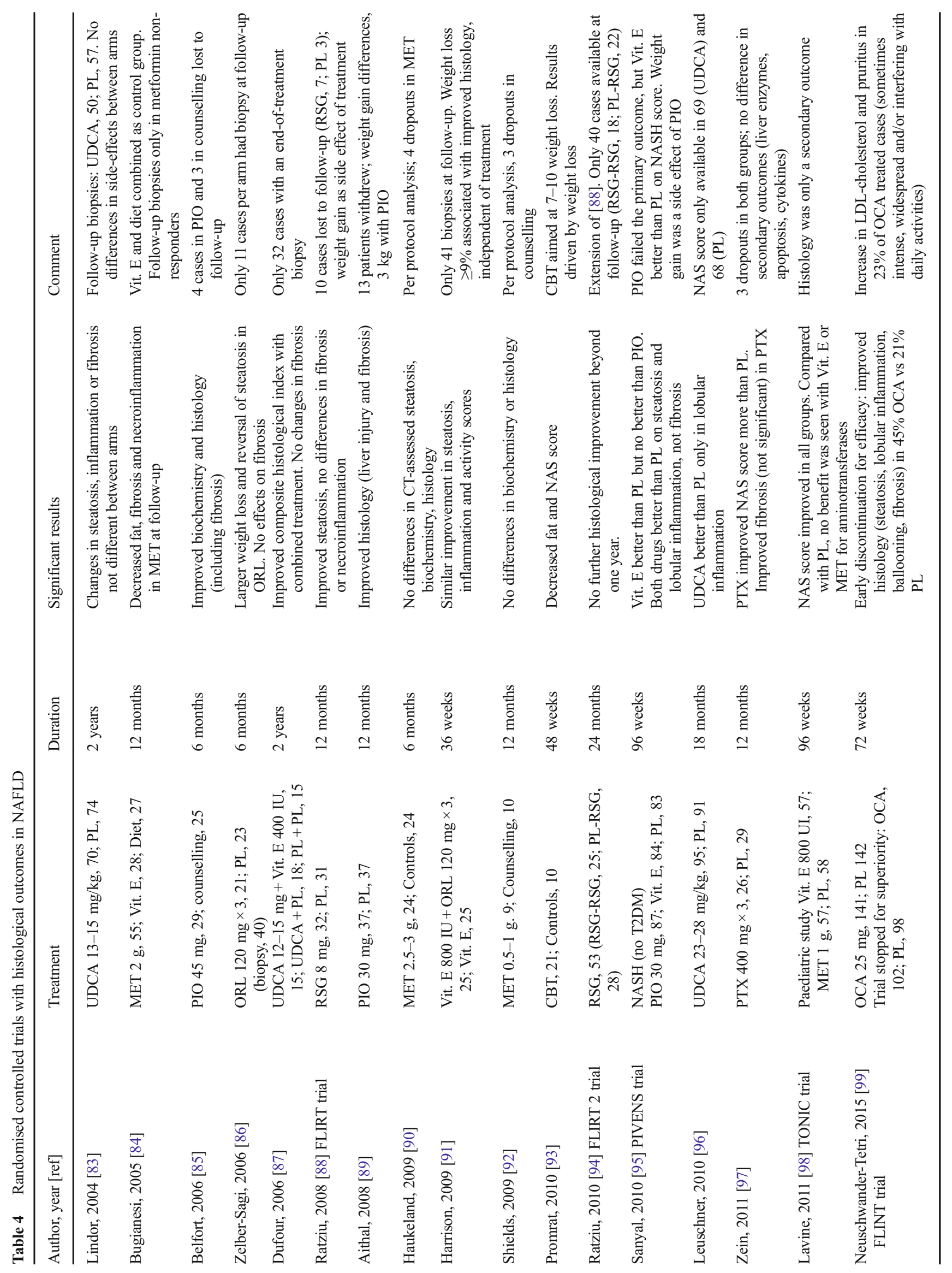




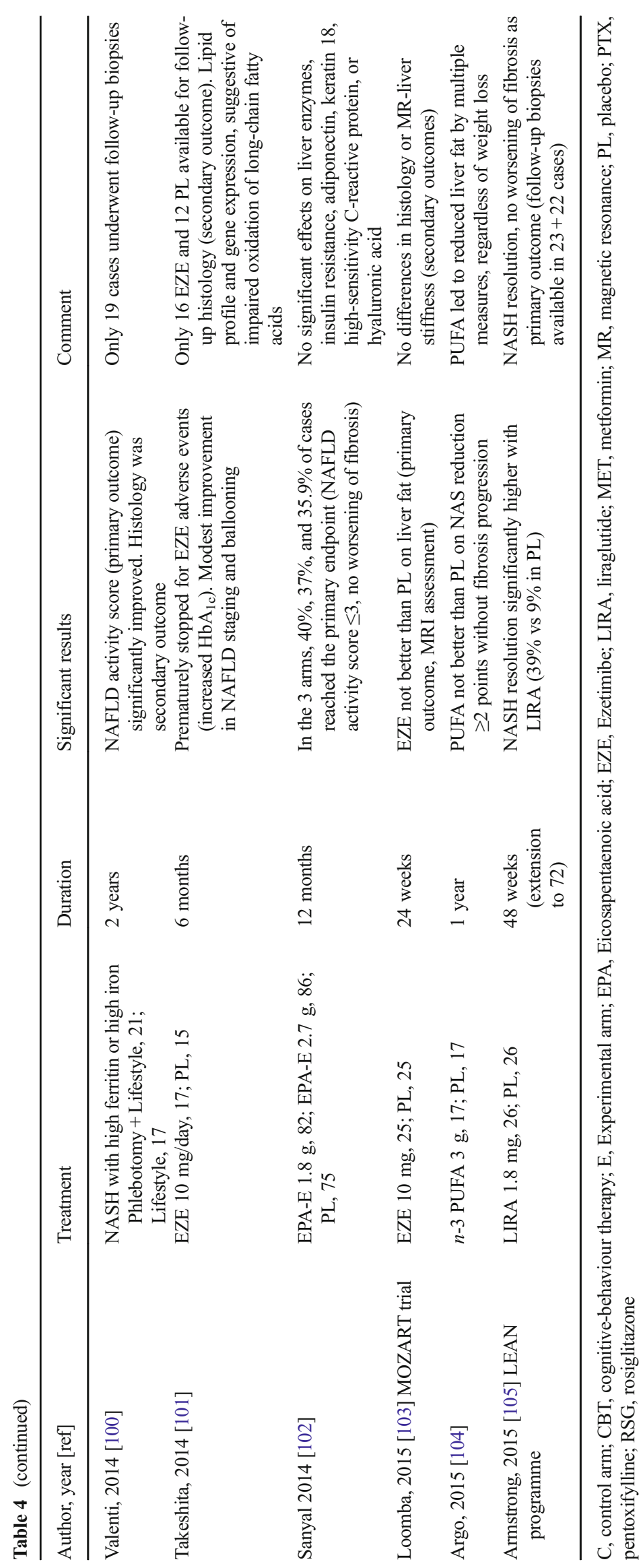


NASH [79]. US-defined NAFLD carries a 1.5- to 2-fold adjusted risk of incident CKD in type 1 diabetes mellitus [80].

NAFLD is also associated with colorectal cancer [81], metabolic bone disease (vitamin D deficiency, osteoporosis) [62, 82] and rare metabolic diseases (lipodystrophies, glycogen storage diseases).

\section{Treatment}

Rationale Successful treatment of NASH should improve outcomes, i.e. decrease NASH-related mortality, reduce progression to cirrhosis or HCC. The resolution of the histological lesions defining NASH is now accepted as a surrogate endpoint, particularly in clinical trials. Only a few properly designed randomised controlled trials (RCTs) are available, with improvement/regression of hepatic necroinflammation and/or fibrosis as primary outcomes [83-105] (Table 4).

\section{Diet and lifestyle changes}

Rationale Epidemiological evidence suggests a tight relationship between unhealthy lifestyle and NAFLD [106], which makes lifestyle correction mandatory in all patients (Table 5). Of note, daily alcohol consumption up to $30 \mathrm{~g}$ (men) or $20 \mathrm{~g}$ (women) is insufficient to induce alcoholic steatosis and might even be protective against NAFLD, NASH and fibrosis as compared with total abstinence.

Relatively small amounts of weight loss reduce liver fat and improve hepatic IR [119]. In a pilot RCT of cognitive-behaviour therapy, lifestyle intervention resulted in more weight loss, more frequent resolution of NASH and a borderline higher $(p=0.05)$ reduction in the NAS score [93]. In a post hoc analysis, a weight loss $\geq 7 \%$ was associated with histological improvement. In an uncontrolled 12-month study with 261 paired biopsies, a modest lifestyle-induced weight loss was associated with NASH regression ( $25 \%$ of total cases) without worsening of fibrosis [120].

Pragmatic approaches combining dietary restriction and a progressive increase in aerobic exercise/resistance training [121] are preferable and should be individually tailored. No data are available on their long-term effects on the natural history of NAFLD.

\section{Recommendations}

- Structured programmes aimed at lifestyle changes towards healthy diet and habitual physical activity are advisable in NAFLD (C2)

- Patients without NASH or fibrosis should only receive counselling for healthy diet and physical activity and no pharmacotherapy for their liver condition (B2)

- In overweight/obese NAFLD, a 7-10\% weight loss is the target of most lifestyle interventions, and results in improvement of liver enzymes and histology (B1)

- Dietary recommendations should consider energy restriction and exclusion of NAFLD-promoting components (processed foods, and foods and beverages high in added fructose). The macronutrient composition should be adjusted according to the Mediterranean diet (B1)

- Both aerobic exercise and resistance training effectively reduce liver fat. The choice of training should be tailored based on patients' preferences to be maintained in the long term (B2)

\section{Drug treatment}

Rationale Drug therapy should be indicated for progressive NASH (bridging fibrosis and cirrhosis) but also for early-stage NASH with increased risk of fibrosis progression (age $>50$ years; diabetes, MetS, increased ALT [122]) or active NASH with high necroinflammatory activity [123]. No drug has currently been tested in phase III trials and is approved for NASH by regulatory agencies. Therefore, no specific therapy can be firmly recommended and any drug treatment would be off-label (for reviews see [124-126], Table 4). Safety and tolerability are essential prerequisites for drug treatment, because of NASH-associated comorbidities and polypharmacy, a potential source of drug-drug interactions.

\section{Insulin sensitisers}

There is scarce evidence for a histological efficacy of metformin in NASH [84, 90, 92]. The effect of metformin on liver fat is weak, because of its inability to restore serum adiponectin levels in the short-term [127]. Some preclinical data support an anti-tumorigenic activity of metformin on liver cancer [128], while the demonstration of reduced rates of $\mathrm{HCC}$ in humans is limited to 
Table 5 Elements of a comprehensive lifestyle approach to NAFLD treatment

\begin{tabular}{|c|c|c|}
\hline Area & Suggested intervention & Supportive literature \\
\hline \multirow[t]{3}{*}{ Energy restriction } & $\begin{array}{l}\text { - 500-1000 kcal energy defect, to induce a } \\
\text { weight loss of } 500-1000 \mathrm{~g} / \text { week }\end{array}$ & $\begin{array}{l}\text { Calorie restriction drives weight loss and } \\
\text { the reduction of liver fat, independent of } \\
\text { the macronutrient composition of the } \\
\text { diet [107] }\end{array}$ \\
\hline & - $7-10 \%$ total weight loss target & $\begin{array}{l}\text { A } 12 \text {-month intensive lifestyle intervention } \\
\text { with an average } 8 \% \text { weight loss leads to } \\
\text { significant reduction of hepatic steatosis } \\
\text { [108]. }\end{array}$ \\
\hline & $\begin{array}{l}\text { - Long-term maintenance approach, } \\
\text { combining physical activity according to } \\
\text { the principles of cognitive-behavioural } \\
\text { treatment }\end{array}$ & $\begin{array}{l}\text { Hepatic fat increases along with total body } \\
\text { fat regain, but most of the beneficial } \\
\text { metabolic effects are maintained and } \\
\text { progression to T2DM is delayed [109]. }\end{array}$ \\
\hline $\begin{array}{l}\text { Macronutrient } \\
\text { composition }\end{array}$ & $\begin{array}{l}\text { - Low-to-moderate fat and moderate-to- } \\
\text { high carbohydrate intake } \\
\text { - Low-carbohydrate ketogenic diets or } \\
\text { high-protein }\end{array}$ & $\begin{array}{l}\text { Adherence to the Mediterranean diet has } \\
\text { been reported to reduce liver fat on }{ }^{1} \mathrm{H}- \\
\text { MRS, when compared with a low fat/ } \\
\text { high carbohydrate diet in a crossover } \\
\text { comparison }[110,111] \text {. }\end{array}$ \\
\hline Fructose intake & $\begin{array}{l}\text { - Avoid fructose-containing beverages and } \\
\text { foods }\end{array}$ & $\begin{array}{l}\text { In the general population, an association } \\
\text { has been reported between high fructose } \\
\text { intake and NAFLD [9] }\end{array}$ \\
\hline Alcohol intake & $\begin{array}{l}\text { - Strictly keep alcohol below the risk } \\
\text { threshold ( } 30 \mathrm{~g}, \text { men; } 20 \mathrm{~g} \text {, women) }\end{array}$ & $\begin{array}{l}\text { In epidemiological surveys, moderate } \\
\text { alcohol intake (namely, wine) below the } \\
\text { risk threshold is associated with lower } \\
\text { prevalence of NAFLD, NASH and even } \\
\text { lower fibrosis at histology [112-114]. } \\
\text { Total abstinence is mandatory in NASH- } \\
\text { cirrhosis to reduce the HCC risk [115]. }\end{array}$ \\
\hline Coffee drinking & - No liver-related limitations & $\begin{array}{l}\text { Protective in NAFLD, as in liver disease of } \\
\text { other aetiologies, reducing histological } \\
\text { severity and liver-related outcomes } \\
\text { [116]. }\end{array}$ \\
\hline $\begin{array}{l}\text { Exercise/physical } \\
\text { activity }\end{array}$ & $\begin{array}{l}\text { - } 150-200 \mathrm{~min} / \text { week of moderate-intensity } \\
\text { aerobic physical activities in } 3-5 \\
\text { sessions are generally preferred (brisk } \\
\text { walking, stationary cycling) } \\
\text { - Resistance training is also effective and } \\
\text { promotes musculoskeletal fitness, with } \\
\text { effects on metabolic risk factors } \\
\text { - High rates of inactivity-promoting fatigue } \\
\text { and daytime sleepiness reduce } \\
\text { compliance with exercise }\end{array}$ & $\begin{array}{l}\text { Physical activity follows a dose-effect } \\
\text { relationship and vigorous (running) } \\
\text { rather than moderate exercise (brisk } \\
\text { walking) carries the full benefit, } \\
\text { including for NASH and fibrosis [110, } \\
\text { 117, 118] } \\
\text { Any engagement in physical activity or } \\
\text { increase over previous levels is however } \\
\text { better than continuing inactivity. }\end{array}$ \\
\hline
\end{tabular}

retrospective studies [129] and insufficient for evidencebased recommendations.

Thiazolidinediones are peroxisome proliferator-activated receptor (PPAR) $\gamma$ agonists with insulin-sensitising effects. The PIVENS trial compared low dose pioglitazone vs vitamin $\mathrm{E}$ vs placebo for 2 years in patients without overt diabetes. Pioglitazone improved all histological features (except for fibrosis) and achieved resolution of NASH more often than placebo [95]. The histological benefit occurred together with ALT improvement and partial correction of IR. Similar results were reported in two smaller and shorter RCTs [85, 89].
Prolonged therapy with rosiglitazone, up to 2 years, did not result in further histological improvement [88, 94], although this was not formally tested with pioglitazone. Side effects of glitazones are of concern: weight gain, bone fractures in women and, rarely, congestive heart failure. Despite the safety and tolerability profile, pioglitazone can be used for selected patients with $\mathrm{NASH}$, particularly in T2DM where the drug has a registered use.

Incretin mimetics, acting on the glucose-insulin interplay have shown favourable results in pre-marketing studies on liver enzymes [130]. A small pilot trial of daily injections of 
liraglutide met the histological outcome of NASH remission without worsening of fibrosis [105].

\section{Antioxidants, cytoprotective and lipid-lowering agents}

In the PIVENS trial, vitamin E (800 IU/day) improved steatosis, inflammation and ballooning and induced resolution of NASH in $36 \%$ of patients $(21 \%$ in the placebo arm) [95]. Reduced ALT correlated with histological improvement, and histological non-responders did not reduce ALT [131]. In the paediatric TONIC trial [98], vitamin E failed to reduce aminotransferases, steatosis and inflammation but improved ballooning and doubled the rate of NASH clearance vs placebo. These results contrast with previous trials, which were mostly negative in both adults and children. Concerns about long-term safety of vitamin E exist, mainly an increase in overall mortality [132], in haemorrhagic stroke [133] and prostate cancer in males older than 50 [134]. Vitamin E may be used in non-cirrhotic non-diabetic NASH patients but further studies are needed before firm recommendations can be made.

Ursodeoxycholic acid (UDCA) has been investigated in several RCTs, at different doses and for up to 2 years, but only showed some biochemical but no histological improvements $[83,87,96]$.

A synthetic farnesoid X receptor agonist, obeticholic acid, improved IR in T2DM [135]. In the phase IIb FLINT trial, a 72-week treatment with obeticholic acid in non-cirrhotic NASH patients, improved all NASH lesions while improving fibrosis [99]. Main issues with safety and tolerability were increased low-density lipoprotein (LDL)-cholesterol and pruritus.

Preliminary data from small or uncontrolled studies suggested that $n-3$ polyunsaturated fatty acids (PUFA) might reduce liver fat [136], but two trials testing PUFA on histological outcomes were negative $[102,104]$. Available data on pentoxifylline and orlistat are limited or inconclusive $[86,91,97]$. Also, data on lipidlowering drugs are poor; recent trials with ezetimibe were negative $[101,103]$, whereas statins have not been adequately tested. Their use in NAFLD is safe, with no increased risk of hepatotoxicity, and may even significantly reduce aminotransferases [137].

Promising novel agents with anti-inflammatory, antifibrotic or insulin-sensitising properties (dual PPAR $\alpha / \delta$ agonists, dual chemokine receptor $[\mathrm{CCR}] 2 /$ CCR5 antagonists and fatty acid/bile acid conjugates) and antifibrotic agents (anti-lysyl oxidase-like [antiLOXL2] monoclonal antibodies) are also being tested in late-phase RCTs in NASH.

\section{Recommendations}

- Pharmacotherapy should be reserved for patients with NASH, particularly for those with significant fibrosis (stage F2 and higher). Patients with less severe disease, but at high risk of disease progression (i.e. with diabetes, MetS, persistently increased ALT, high necroinflammation) could also be candidates to prevent disease progression (B1)

- While no firm recommendations can be made, pioglitazone (most efficacy data, but off-label outside T2DM) or vitamin E (better safety and tolerability in the short term) or their combination could be used for NASH (B2)

- The optimal duration of therapy is unknown; in patients with increased ALT at baseline, treatment should be stopped if there is no reduction in aminotransferases after 6 months of therapy; in patients with normal ALT at baseline, no recommendations can be made (C2)

- Statins may be confidently used to reduce LDLcholesterol and prevent cardiovascular risk, with no benefits or harm on liver disease. Similarly $n-3$ polyunsaturated fatty acids reduce both plasma and liver lipids, but there are no data to support their use specifically for NASH (B1)

\section{Iron depletion}

Hepatic iron accumulation is associated with IR, and iron depletion improves IR [138]. In NAFLD, high ferritin levels are common, in the presence of variable transferrin saturation, independent of gene polymorphisms of familial haemochromatosis. In these patients, a phlebotomy programme to reduce iron stores to near iron deficiency improved the NAS score, without worsening fibrosis [100], but more data are needed.

\section{Paediatric NAFLD}

In children, diet and exercise training reduce steatosis, but do not affect ballooning, inflammation and fibrosis [139]. Although several drug-based therapies, such as vitamin E and metformin, and dietary supplementation, including probiotics and docosahexaenoic acid, have shown beneficial effects on ballooning, steatosis and inflammation, fibrotic lesions are refractory to treatment [140] and the long-term outcome of paediatric NASH remains poor [141]. 


\section{Recommendations}

- Diet and physical activity improve steatosis and hepatic inflammation in paediatric NAFLD, but no beneficial effects on fibrosis have ever been demonstrated. No safe drug treatment has proven effective on fibrosis in paediatric NAFLD (B1)

\section{Bariatric (metabolic) surgery}

In patients unresponsive to lifestyle changes and pharmacotherapy, bariatric surgery is an option for reducing weight and metabolic complications, with stable results in the long term [142]. Surrogate markers indicate that bariatric surgery is effective on NAFLD-associated liver injury, and there is also initial evidence for improved necroinflammation and fibrosis [143]. A recent cohort study with 1-year follow-up confirmed that bariatric surgery-associated weight loss cleared NASH in $85 \%$ of patients and improved fibrosis in 34\% [144], although the possible benefits should be balanced against peri-/post-operative complications. No solid data on the comparative effects of different bariatric procedures on liver fat are available.

\section{Recommendations}

- By improving obesity and diabetes, bariatric (metabolic) surgery reduces liver fat and is likely to reduce NASH progression; prospective data have shown an improvement in all histological lesions of NASH, including fibrosis (B1)

\section{Liver transplantation}

NAFLD-associated cirrhosis is among the top three indications for liver transplantation. The 3- and 5-year survival is not different in NAFLD vs no NAFLD; NAFLD carries a higher risk of death from cardiovascular complications and sepsis, whereas the risk of graft failure is lower $[145,146]$. The overall mortality is associated with BMI and diabetes, with $50 \%$ of cases with BMI $>35 \mathrm{~kg} / \mathrm{m}^{2}$ dying within 1 year of transplantation [147]. Transplant failure $(10 \%$ and $45 \%$ at 10 and 20 years, respectively [148]) in obese patients is rarely associated with recurrent NASH cirrhosis $(\approx 2 \%)$ [146].

\section{Recommendations}

- Liver transplantation is an accepted procedure in NASH patients with end-stage liver disease, with comparable overall survival to other indications, despite a higher cardiovascular mortality. NASH patients with liver failure and/or HCC are candidates for liver transplantation (A1)

Acknowledgements We would like to thank the reviewers of these Clinical Practice Guidelines for their time and critical reviewing: Professor Elisabetta Bugianesi (Department of Medical Sciences, University of Turin, Turin, Italy), Professor Helena Cortez-Pinto (Unidade de Nutrição e Metabolismo, Faculdade de Medicina de Lisboa, Lisbon, Portugal) and Dr Stephen Harrison (Brooke Army Medical Center, San Antonio, TX, USA).

Duality of interest Giulio Marchesini declares he does not have anything to disclose regarding funding or conflict of interest with respect to this manuscript.

Christopher P. Day declares he has been a consultant/advisor for Abbott Laboratories and Genfit and completed sponsored lectures for Abbott Laboratories.

Jean-François Dufour declares he has been a consultant/advisor for Intercept and Genfit.

Ali Canbay declares he does not have anything to disclose regarding funding or conflict of interest with respect to this manuscript.

Valerio Nobili declares he does not have anything to disclose regarding funding or conflict of interest with respect to this manuscript.

Vlad Ratziu declares he has been a consultant/advisor for Genfit. In addition he has been on the advisory board for Gilead, Genfit, Roche and Galmed Pharmaceuticals.

Herbert Tilg declares he does not have anything to disclose regarding funding or conflict of interest with respect to this manuscript.

Michael Roden has received research support and been involved in clinical trials for Boehringer Ingelheim, Novartis Pharma and Sanofi-Aventis Germany. He has been a consultant/ advisor for GI Dynamics, Sanofi-Aventis Germany and Merck \& Co. Inc. He has completed sponsored lectures for Eli Lilly and Novo Nordisk.

Amalia Gastaldelli has received research support from Amylin-BMSAstraZeneca and has been a consultant/advisor for Roche, Eli-Lilly and Sanofi Aventis.

Hannele Yki-Järvinen declares she does not have anything to disclose regarding funding or conflict of interest with respect to this manuscript.

Fritz Schick declares he does not have anything to disclose regarding funding or conflict of interest with respect to this manuscript.

Roberto Vettor declares that he has been a consultant/advisor as well as received grants/research support from Sanofi. In addition he has completed sponsored lectures for Novo Nordisk, Sanofi and AstraZeneca.

Gema Frühbeck declares that she is on the Novo Nordisk Obesity Scientific Communication Global Advisory Board.

Lisbeth Mathus-Vliegen declares she does not have anything to disclose regarding funding or conflict of interest with respect to this manuscript. 


\section{References}

1. Ratziu V, Bellentani S, Cortez-Pinto H, Day C, Marchesini G (2010) A position statement on NAFLD/NASH based on the EASL 2009 special conference. J Hepatol 53:372-384

2. Guyatt GH, Oxman AD, Vist GE et al (2008) GRADE: an emerging consensus on rating quality of evidence and strength of recommendations. BMJ 336:924-926

3. Bellentani S, Saccoccio G, Masutti F et al (2000) Prevalence of and risk factors for hepatic steatosis in Northern Italy. Ann Intern Med 132:112-117

4. Vernon G, Baranova A, Younossi ZM (2011) Systematic review: the epidemiology and natural history of non-alcoholic fatty liver disease and non-alcoholic steatohepatitis in adults. Aliment Pharmacol Ther 34:274-285

5. Younossi ZM, Stepanova M, Negro F et al (2012) Nonalcoholic fatty liver disease in lean individuals in the United States. Medicine (Baltimore) 91:319-327

6. Fracanzani AL, Valenti L, Bugianesi E et al (2008) Risk of severe liver disease in NAFLD with normal aminotransferase levels: a role for insulin resistance and diabetes. Hepatology 48:792-798

7. Marchesini G, Mazzotti A (2015) NAFLD incidence and remission: only a matter of weight gain and weight loss? J Hepatol 62:15-17

8. Chalasani N, Younossi Z, Lavine JE et al (2012) The diagnosis and management of non-alcoholic fatty liver disease: practice Guideline by the American Association for the Study of Liver Diseases, American College of Gastroenterology, and the American Gastroenterological Association. Hepatology 55:2005-2023

9. Barrera F, George J (2014) The role of diet and nutritional intervention for the management of patients with NAFLD. Clin Liver Dis 18:91-112

10. Chiu S, Sievenpiper JL, de Souza RJ et al (2014) Effect of fructose on markers of non-alcoholic fatty liver disease (NAFLD): a systematic review and meta-analysis of controlled feeding trials. Eur J Clin Nutr 68:416-423

11. Gerber L, Otgonsuren M, Mishra A et al (2012) Non-alcoholic fatty liver disease (NAFLD) is associated with low level of physical activity: a population-based study. Aliment Pharmacol Ther 36:772-781

12. Anstee QM, Targher G, Day CP (2013) Progression of NAFLD to diabetes mellitus, cardiovascular disease or cirrhosis. Nat Rev Gastroenterol Hepatol 10:330-344

13. Valenti L, Al-Serri A, Daly AK et al (2010) Homozygosity for the patatin-like phospholipase-3/adiponutrin I148M polymorphism influences liver fibrosis in patients with nonalcoholic fatty liver disease. Hepatology 51:1209-1217

14. Liu YL, Patman GL, Leathart JB et al (2014) Carriage of the PNPLA3 rs738409 $\mathrm{C}>\mathrm{G}$ polymorphism confers an increased risk of non-alcoholic fatty liver disease associated hepatocellular carcinoma. J Hepatol 61:75-81

15. Liu YL, Reeves HL, Burt AD et al (2014) TM6SF2 rs58542926 influences hepatic fibrosis progression in patients with nonalcoholic fatty liver disease. Nat Commun 5:4309

16. Dongiovanni P, Petta S, Maglio C et al (2015) Transmembrane 6 superfamily member 2 gene variant disentangles nonalcoholic steatohepatitis from cardiovascular disease. Hepatology 61:506514

17. Valenti L, Alisi A, Galmozzi E et al (2010) I148M patatin-like phospholipase domain-containing 3 gene variant and severity of pediatric nonalcoholic fatty liver disease. Hepatology 52:1274 1280
18. Nobili V, Donati B, Panera N et al (2014) A 4-polymorphism risk score predicts steatohepatitis in children with nonalcoholic fatty liver disease. J Pediatr Gastroenterol Nutr 58:632-636

19. Ratziu V, Charlotte F, Heurtier A et al (2005) Sampling variability of liver biopsy in nonalcoholic fatty liver disease. Gastroenterology 128:1898-1906

20. Kleiner DE, Brunt EM (2012) Nonalcoholic fatty liver disease: pathologic patterns and biopsy evaluation in clinical research. Semin Liver Dis 32:3-13

21. Kleiner DE, Brunt EM, Van Natta M et al (2005) Design and validation of a histological scoring system for nonalcoholic fatty liver disease. Hepatology 41:1313-1321

22. Bedossa P, Pathology Consortium FLIP (2014) Utility and appropriateness of the fatty liver inhibition of progression (FLIP) algorithm and steatosis, activity, and fibrosis (SAF) score in the evaluation of biopsies of nonalcoholic fatty liver disease. Hepatology 60:565-575

23. Brunt EM, Kleiner DE, Wilson LA, Belt P, Neuschwander-Tetri BA, NASH Clinical Research Network (CRN) (2011) Nonalcoholic fatty liver disease (NAFLD) activity score and the histopathologic diagnosis in NAFLD: distinct clinicopathologic meanings. Hepatology 53:810-820

24. Ekstedt M, Hagstrom H, Nasr P et al (2015) Fibrosis stage is the strongest predictor for disease-specific mortality in NAFLD after up to 33 years of follow-up. Hepatology 61:1547-1554

25. Brunt EM, Kleiner DE, Wilson LA et al (2009) Portal chronic inflammation in nonalcoholic fatty liver disease (NAFLD): a histologic marker of advanced NAFLD-Clinicopathologic correlations from the nonalcoholic steatohepatitis clinical research network. Hepatology 49:809-820

26. Alkhouri N, De Vito R, Alisi A et al (2012) Development and validation of a new histological score for pediatric non-alcoholic fatty liver disease. J Hepatol 57:1312-1318

27. Saadeh S, Younossi ZM, Remer EM et al (2002) The utility of radiological imaging in nonalcoholic fatty liver disease. Gastroenterology 123:745-750

28. Fishbein M, Castro F, Cheruku S et al (2005) Hepatic MRI for fat quantitation: its relationship to fat morphology, diagnosis, and ultrasound. J Clin Gastroenterol 39:619-625

29. Ryan CK, Johnson LA, Germin BI, Marcos A (2002) One hundred consecutive hepatic biopsies in the workup of living donors for right lobe liver transplantation. Liver Transpl 8:1114-1122

30. Fedchuk L, Nascimbeni F, Pais R et al (2014) Performance and limitations of steatosis biomarkers in patients with nonalcoholic fatty liver disease. Aliment Pharmacol Ther 40:1209-1222

31. Machado MV, Cortez-Pinto H (2013) Non-invasive diagnosis of non-alcoholic fatty liver disease. A critical appraisal. J Hepatol 58: 1007-1019

32. European Association for the Study of the Liver, Asociacion Latinoamericana para el Estudio del Higado (2015) EASLALEH Clinical Practice Guidelines: non-invasive tests for evaluation of liver disease severity and prognosis. J Hepatol 63:237-264

33. Cusi K, Chang Z, Harrison S et al (2014) Limited value of plasma cytokeratin-18 as a biomarker for NASH and fibrosis in patients with non-alcoholic fatty liver disease. J Hepatol 60:167-174

34. Kwok R, Tse YK, Wong GL et al (2014) Systematic review with meta-analysis: non-invasive assessment of non-alcoholic fatty liver disease-the role of transient elastography and plasma cytokeratin-18 fragments. Aliment Pharmacol Ther 39:254-269

35. Vuppalanchi R, Jain AK, Deppe R et al (2014) Relationship between changes in serum levels of keratin 18 and changes in liver histology in children and adults with nonalcoholic fatty liver disease. Clin Gastroenterol Hepatol 12:2121-2130, e2121-2122

36. Guha IN, Parkes J, Roderick P et al (2008) Noninvasive markers of fibrosis in nonalcoholic fatty liver disease: validating the 
European Liver Fibrosis Panel and exploring simple markers. Hepatology 47:455-460

37. McPherson S, Anstee QM, Henderson E, Day CP, Burt AD (2013) Are simple noninvasive scoring systems for fibrosis reliable in patients with NAFLD and normal ALT levels? Eur J Gastroenterol Hepatol 25:652-658

38. Wong VW, Vergniol J, Wong GL et al (2010) Diagnosis of fibrosis and cirrhosis using liver stiffness measurement in nonalcoholic fatty liver disease. Hepatology 51:454-462

39. Castera L, Foucher J, Bernard PH et al (2010) Pitfalls of liver stiffness measurement: a 5-year prospective study of 13,369 examinations. Hepatology 51:828-835

40. Wong VW, Vergniol J, Wong GL et al (2012) Liver stiffness measurement using XL probe in patients with nonalcoholic fatty liver disease. Am J Gastroenterol 107:1862-1871

41. Petta S, Vanni E, Bugianesi E et al (2015) The combination of liver stiffness measurement and NAFLD fibrosis score improves the noninvasive diagnostic accuracy for severe liver fibrosis in patients with nonalcoholic fatty liver disease. Liver Int 35:1566-1573

42. Vajro P, Lenta S, Socha P et al (2012) Diagnosis of nonalcoholic fatty liver disease in children and adolescents: position paper of the ESPGHAN Hepatology Committee. J Pediatr Gastroenterol Nutr 54:700-713

43. Nobili V, Svegliati-Baroni G, Alisi A, Miele L, Valenti L, Vajro P (2013) A 360-degree overview of paediatric NAFLD: recent insights. J Hepatol 58:1218-1229

44. Gaggini M, Morelli M, Buzzigoli E, DeFronzo RA, Bugianesi E, Gastaldelli A (2013) Non-alcoholic fatty liver disease (NAFLD) and its connection with insulin resistance, dyslipidemia, atherosclerosis and coronary heart disease. Nutrients 5:1544-1560

45. Alberti A, Vario A, Ferrari A, Pistis R (2005) Review article: chronic hepatitis $\mathrm{C}$-natural history and cofactors. Aliment Pharmacol Ther 22(Suppl 2):74-78

46. Koliaki C, Szendroedi J, Kaul K et al (2015) Adaptation of hepatic mitochondrial function in humans with non-alcoholic fatty liver is lost in steatohepatitis. Cell Metab 21:739-746

47. Yki-Järvinen H (2014) Non-alcoholic fatty liver disease as a cause and a consequence of metabolic syndrome. Lancet Diabetes Endocrinol 2:901-910

48. Matthews DR, Hosker JP, Rudenski AS, Naylor BA, Treacher DF, Turner RC (1985) Homeostasis model assessment: insulin resistance and beta-cell function from fasting plasma glucose and insulin concentrations in man. Diabetologia 28:412-419

49. McPherson S, Hardy T, Henderson E, Burt AD, Day CP, Anstee QM (2015) Evidence of NAFLD progression from steatosis to fibrosing-steatohepatitis using paired biopsies: implications for prognosis and clinical management. J Hepatol 62:1148-1155

50. Pais R, Charlotte F, Fedchuk L et al (2013) A systematic review of follow-up biopsies reveals disease progression in patients with non-alcoholic fatty liver. J Hepatol 59:550-556

51. Bedogni G, Miglioli L, Masutti F, Tiribelli C, Marchesini G, Bellentani S (2005) Prevalence of and risk factors for nonalcoholic fatty liver disease: the Dionysos nutrition and liver study. Hepatology 42:44-52

52. Frith J, Day CP, Robinson L, Elliott C, Jones DE, Newton JL (2010) Potential strategies to improve uptake of exercise interventions in non-alcoholic fatty liver disease. J Hepatol 52:112-116

53. Caldwell SH, Crespo DM (2004) The spectrum expanded: cryptogenic cirrhosis and the natural history of non-alcoholic fatty liver disease. J Hepatol 40:578-584

54. Aron-Wisnewsky J, Minville C, Tordjman J et al (2012) Chronic intermittent hypoxia is a major trigger for non-alcoholic fatty liver disease in morbid obese. J Hepatol 56:225-233

55. Gomez-Ambrosi J, Silva C, Galofre JC et al (2012) Body mass index classification misses subjects with increased cardiometabolic risk factors related to elevated adiposity. Int J Obes (Lond) 36:286-294

56. Chang Y, Ryu S, Suh BS, Yun KE, Kim CW, Cho SI (2012) Impact of BMI on the incidence of metabolic abnormalities in metabolically healthy men. Int J Obes (Lond) 36:1187-1194

57. Gomez-Ambrosi J, Catalan V, Rodriguez A et al (2014) Increased cardiometabolic risk factors and inflammation in adipose tissue in obese subjects classified as metabolically healthy. Diabetes Care 37:2813-2821

58. Ghouri N, Preiss D, Sattar N (2010) Liver enzymes, nonalcoholic fatty liver disease, and incident cardiovascular disease: a narrative review and clinical perspective of prospective data. Hepatology 52:1156-1161

59. Gastaldelli A, Cusi K, Pettiti M et al (2007) Relationship between hepatic/visceral fat and hepatic insulin resistance in nondiabetic and type 2 diabetic subjects. Gastroenterology 133:496-506

60. Kotronen A, Juurinen L, Hakkarainen A et al (2008) Liver fat is increased in type 2 diabetic patients and underestimated by serum alanine aminotransferase compared with equally obese nondiabetic subjects. Diabetes Care 31:165-169

61. Loomba R, Abraham M, Unalp A et al (2012) Association between diabetes, family history of diabetes, and risk of nonalcoholic steatohepatitis and fibrosis. Hepatology 56:943-951

62. Armstrong MJ, Adams LA, Canbay A, Syn WK (2014) Extrahepatic complications of nonalcoholic fatty liver disease. Hepatology 59:1174-1197

63. American Diabetes Association (2014) Standards of medical care in diabetes-2014. Diabetes Care 37(Suppl 1):S14-S80

64. Ortiz-Lopez C, Lomonaco R, Orsak B et al (2012) Prevalence of prediabetes and diabetes and metabolic profile of patients with nonalcoholic fatty liver disease (NAFLD). Diabetes Care 35: 873-878

65. Juurinen L, Tiikkainen M, Häkkinen AM, Hakkarainen A, YkiJärvinen H (2007) Effects of insulin therapy on liver fat content and hepatic insulin sensitivity in patients with type 2 diabetes. Am J Physiol Endocrinol Metab 292:E829-E835

66. Llaurado G, Sevastianova K, Sadevirta S et al (2015) Liver fat content and hepatic insulin sensitivity in overweight patients with type 1 diabetes. J Clin Endocrinol Metab 100:607-616

67. Anderwald C, Bernroider E, Krssak M et al (2002) Effects of insulin treatment in type 2 diabetic patients on intracellular lipid content in liver and skeletal muscle. Diabetes 51:3025-3032

68. Singh S, Allen AM, Wang Z, Prokop LJ, Murad MH, Loomba R (2015) Fibrosis progression in nonalcoholic fatty liver vs nonalcoholic steatohepatitis: a systematic review and meta-analysis of paired-biopsy studies. Clin Gastroenterol Hepatol 13:643-654, e641-649; quiz e639-640

69. Haflidadottir S, Jonasson JG, Norland H et al (2014) Long-term follow-up and liver-related death rate in patients with nonalcoholic and alcoholic related fatty liver disease. BMC Gastroenterol 14:166

70. Kim D, Kim WR, Kim HJ, Therneau TM (2013) Association between noninvasive fibrosis markers and mortality among adults with nonalcoholic fatty liver disease in the United States. Hepatology 57:1357-1365

71. Schwimmer JB, Behling C, Newbury R et al (2005) Histopathology of pediatric nonalcoholic fatty liver disease. Hepatology 42:641-649

72. Oni ET, Agatston AS, Blaha MJ et al (2013) A systematic review: burden and severity of subclinical cardiovascular disease among those with nonalcoholic fatty liver; should we care? Atherosclerosis 230:258-267

73. Targher G, Day CP, Bonora E (2010) Risk of cardiovascular disease in patients with nonalcoholic fatty liver disease. $\mathrm{N}$ Engl $\mathrm{J}$ Med 363:1341-1350 
74. Bhatia LS, Curzen NP, Calder PC, Byrne CD (2012) Nonalcoholic fatty liver disease: a new and important cardiovascular risk factor? Eur Heart J 33:1190-1200

75. Calori G, Lattuada G, Ragogna F et al (2011) Fatty liver index and mortality: the Cremona study in the 15th year of follow-up. Hepatology 54:145-152

76. Pacifico L, Chiesa C, Anania C, De Merulis A, Osborn JF, Romaggioli S et al (2014) Nonalcoholic fatty liver disease and the heart in children and adolescents. World J Gastroenterol 20:9055-9071

77. Dyson J, Jaques B, Chattopadyhay D et al (2014) Hepatocellular cancer: the impact of obesity, type 2 diabetes and a multidisciplinary team. J Hepatol 60:110-117

78. Wong RJ, Cheung R, Ahmed A (2014) Nonalcoholic steatohepatitis is the most rapidly growing indication for liver transplantation in patients with hepatocellular carcinoma in the U.S. Hepatology 59:2188-2195

79. Musso G, Gambino R, Tabibian JH et al (2014) Association of non-alcoholic fatty liver disease with chronic kidney disease: a systematic review and meta-analysis. PLoS Med 11, e1001680

80. Targher G, Bertolini L, Chonchol M et al (2010) Non-alcoholic fatty liver disease is independently associated with an increased prevalence of chronic kidney disease and retinopathy in type 1 diabetic patients. Diabetologia 53:1341-1348

81. Kim NH, Park J, Kim SH et al (2014) Non-alcoholic fatty liver disease, metabolic syndrome and subclinical cardiovascular changes in the general population. Heart 100:938-943

82. Hazlehurst JM, Tomlinson JW (2013) Non-alcoholic fatty liver disease in common endocrine disorders. Eur J Endocrinol 169:R27-R37

83. Lindor KD, Kowdley KV, Heathcote EJ et al (2004) Ursodeoxycholic acid for treatment of nonalcoholic steatohepatitis: results of a randomized trial. Hepatology 39:770-778

84. Bugianesi E, Gentilcore E, Manini R et al (2005) A randomized controlled trial of metformin versus vitamin $\mathrm{E}$ or prescriptive diet in nonalcoholic fatty liver disease. Am J Gastroenterol 100:1082-1090

85. Belfort R, Harrison SA, Brown K et al (2006) A placebocontrolled trial of pioglitazone in subjects with nonalcoholic steatohepatitis. N Engl J Med 355:2297-2307

86. Zelber-Sagi S, Kessler A, Brazowsky E et al (2006) A doubleblind randomized placebo-controlled trial of orlistat for the treatment of nonalcoholic fatty liver disease. Clin Gastroenterol Hepatol 4:639-644

87. Dufour JF, Oneta CM, Gonvers JJ et al (2006) Randomized placebo-controlled trial of ursodeoxycholic acid with vitamin $\mathrm{E}$ in nonalcoholic steatohepatitis. Clin Gastroenterol Hepatol 4:1537-1543

88. Ratziu V, Giral P, Jacqueminet S et al (2008) Rosiglitazone for nonalcoholic steatohepatitis: one-year results of the randomized placebo-controlled Fatty Liver Improvement with Rosiglitazone Therapy (FLIRT) Trial. Gastroenterology 135:100-110

89. Aithal GP, Thomas JA, Kaye PV et al (2008) Randomized, placebo-controlled trial of pioglitazone in nondiabetic subjects with nonalcoholic steatohepatitis. Gastroenterology 135:1176-1184

90. Haukeland JW, Konopski Z, Eggesbo HB et al (2009) Metformin in patients with non-alcoholic fatty liver disease: a randomized, controlled trial. Scand J Gastroenterol 44:853-860

91. Harrison SA, Fecht W, Brunt EM, Neuschwander-Tetri BA (2009) Orlistat for overweight subjects with nonalcoholic steatohepatitis: a randomized, prospective trial. Hepatology 49:80-86

92. Shields WW, Thompson KE, Grice GA, Harrison SA, Coyle WJ (2009) The effect of metformin and standard therapy versus standard therapy alone in nondiabetic patients with insulin resistance and nonalcoholic steatohepatitis (NASH): a pilot trial. Therap Adv Gastroenterol 2:157-163

93. Promrat K, Kleiner DE, Niemeier HM et al (2010) Randomized controlled trial testing the effects of weight loss on nonalcoholic steatohepatitis. Hepatology 51:121-129

94. Ratziu V, Charlotte F, Bernhardt C et al (2010) Long-term efficacy of rosiglitazone in nonalcoholic steatohepatitis: results of the fatty liver improvement by rosiglitazone therapy (FLIRT 2) extension trial. Hepatology 51:445-453

95. Sanyal AJ, Chalasani N, Kowdley KV et al (2010) Pioglitazone, vitamin $\mathrm{E}$, or placebo for nonalcoholic steatohepatitis. N Engl J Med 362:1675-1685

96. Leuschner UF, Lindenthal B, Herrmann G et al (2010) High-dose ursodeoxycholic acid therapy for nonalcoholic steatohepatitis: a double-blind, randomized, placebo-controlled trial. Hepatology 52:472-479

97. Zein CO, Yerian LM, Gogate P et al (2011) Pentoxifylline improves nonalcoholic steatohepatitis: a randomized placebocontrolled trial. Hepatology 54:1610-1619

98. Lavine JE, Schwimmer JB, Van Natta ML et al (2011) Effect of vitamin $\mathrm{E}$ or metformin for treatment of nonalcoholic fatty liver disease in children and adolescents: the TONIC randomized controlled trial. JAMA 305:1659-1668

99. Neuschwander-Tetri BA, Loomba R, Sanyal AJ et al (2015) Farnesoid X nuclear receptor ligand obeticholic acid for non-cirrhotic, non-alcoholic steatohepatitis (FLINT): a multicentre, randomised, placebo-controlled trial. Lancet 385:956-965

100. Valenti L, Fracanzani AL, Dongiovanni P et al (2014) A randomized trial of iron depletion in patients with nonalcoholic fatty liver disease and hyperferritinemia. World J Gastroenterol 20:30023010

101. Takeshita Y, Takamura T, Honda M et al (2014) The effects of ezetimibe on non-alcoholic fatty liver disease and glucose metabolism: a randomised controlled trial. Diabetologia 57:878-890

102. Sanyal AJ, Abdelmalek MF, Suzuki A, Cummings OW, Chojkier M, EPE-A Study Group (2014) No significant effects of ethyleicosapentanoic acid on histologic features of nonalcoholic steatohepatitis in a phase 2 trial. Gastroenterology 147:377384.e1

103. Loomba R, Sirlin CB, Ang B et al (2015) Ezetimibe for the treatment of nonalcoholic steatohepatitis: assessment by novel magnetic resonance imaging and magnetic resonance elastography in a randomized trial (MOZART trial). Hepatology 61:1239-1250

104. Argo CK, Patrie JT, Lackner C et al (2015) Effects of n-3 fish oil on metabolic and histological parameters in NASH: a double-blind, randomized, placebo-controlled trial. J Hepatol 62:190-197

105. Armstrong MJ, Gaunt P, Aithal GP et al (2015) Liraglutide safety and efficacy in patients with non-alcoholic steatohepatitis (LEAN): a multicentre, double-blind, randomised, placebocontrolled phase 2 study. Lancet 387:679-690

106. Zelber-Sagi S, Ratziu V, Oren R (2011) Nutrition and physical activity in NAFLD: an overview of the epidemiological evidence. World J Gastroenterol 17:3377-3389

107. Boden G (2009) High- or low-carbohydrate diets: which is better for weight loss, insulin resistance, and fatty livers? Gastroenterology 136:1490-1492

108. Lazo M, Solga SF, Horska A et al (2010) Effect of a 12-month intensive lifestyle intervention on hepatic steatosis in adults with type 2 diabetes. Diabetes Care 33:2156-2163

109. Perreault L, Pan Q, Mather KJ, Watson KE, Hamman RF, Kahn SE (2012) Effect of regression from prediabetes to normal glucose regulation on long-term reduction in diabetes risk: results from the Diabetes Prevention Program Outcomes Study. Lancet 379:2243-2251 
110. Thoma C, Day CP, Trenell MI (2012) Lifestyle interventions for the treatment of non-alcoholic fatty liver disease in adults: a systematic review. J Hepatol 56:255-266

111. Ryan MC, Itsiopoulos C, Thodis T et al (2013) The Mediterranean diet improves hepatic steatosis and insulin sensitivity in individuals with non-alcoholic fatty liver disease. J Hepatol 59:138-143

112. Liangpunsakul S, Chalasani N (2012) What should we recommend to our patients with NAFLD regarding alcohol use? Am J Gastroenterol 107:976-978

113. Kwon HK, Greenson JK, Conjeevaram HS (2014) Effect of lifetime alcohol consumption on the histological severity of nonalcoholic fatty liver disease. Liver Int 34:129-135

114. Dunn W, Sanyal AJ, Brunt EM et al (2012) Modest alcohol consumption is associated with decreased prevalence of steatohepatitis in patients with non-alcoholic fatty liver disease (NAFLD). J Hepatol 57:384-391

115. Ascha MS, Hanouneh IA, Lopez R, Tamimi TA, Feldstein AF, Zein NN (2010) The incidence and risk factors of hepatocellular carcinoma in patients with nonalcoholic steatohepatitis. Hepatology 51:1972-1978

116. Saab S, Mallam D, Cox GA 2nd, Tong MJ (2014) Impact of coffee on liver diseases: a systematic review. Liver Int 34:495-504

117. Keating SE, Hackett DA, George J, Johnson NA (2012) Exercise and non-alcoholic fatty liver disease: a systematic review and meta-analysis. J Hepatol 57:157-166

118. Bacchi E, Negri C, Targher G et al (2013) Both resistance training and aerobic training reduce hepatic fat content in type 2 diabetic subjects with nonalcoholic fatty liver disease (the RAED2 Randomized Trial). Hepatology 58:1287-1295

119. Petersen KF, Dufour S, Befroy D, Lehrke M, Hendler RE, Shulman GI (2005) Reversal of nonalcoholic hepatic steatosis, hepatic insulin resistance, and hyperglycemia by moderate weight reduction in patients with type 2 diabetes. Diabetes 54:603-608

120. Vilar-Gomez E, Martinez-Perez Y, Calzadilla-Bertot L et al (2015) Weight loss via lifestyle modification significantly reduces features of nonalcoholic steatohepatitis. Gastroenterology 149:36778.e5, quiz e14-e15

121. Rodriguez B, Torres DM, Harrison SA (2012) Physical activity: an essential component of lifestyle modification in NAFLD. Nat Rev Gastroenterol Hepatol 9:726-731

122. Adams LA, Sanderson S, Lindor KD, Angulo P (2005) The histological course of nonalcoholic fatty liver disease: a longitudinal study of 103 patients with sequential liver biopsies. J Hepatol 42:132-138

123. Sanyal AJ, Friedman SL, McCullough AJ, Dimick-Santos L, American Association for the Study of Liver Diseases, United States Food and Drug Administration (2015) Challenges and opportunities in drug and biomarker development for nonalcoholic steatohepatitis: findings and recommendations from an American Association for the Study of Liver Diseases-U.S. Food and Drug Administration Joint Workshop. Hepatology 61:1392-1405

124. Younossi ZM, Reyes MJ, Mishra A, Mehta R, Henry L (2014) Systematic review with meta-analysis: non-alcoholic steatohepatitis - a case for personalised treatment based on pathogenic targets. Aliment Pharmacol Ther 39:3-14

125. Mazzella N, Ricciardi LM, Mazzotti A, Marchesini G (2014) The role of medications for the management of patients with NAFLD. Clin Liver Dis 18:73-89

126. Ratziu V, Goodman Z, Sanyal A (2015) Current efforts and trends in the treatment of NASH. J Hepatol 62:S65-S75

127. Tiikkainen M, Häkkinen AM, Korsheninnikova E, Nyman T, Makimattila S, Yki-Järvinen H (2004) Effects of rosiglitazone and metformin on liver fat content, hepatic insulin resistance, insulin clearance, and gene expression in adipose tissue in patients with type 2 diabetes. Diabetes 53:2169-2176
128. Bhalla K, Hwang BJ, Dewi RE et al (2012) Metformin prevents liver tumorigenesis by inhibiting pathways driving hepatic lipogenesis. Cancer Prev Res (Phila) 5:544-552

129. Zhang ZJ, Zheng ZJ, Shi R, Su Q, Jiang Q, Kip KE (2012) Metformin for liver cancer prevention in patients with type 2 diabetes: a systematic review and meta-analysis. J Clin Endocrinol Metab 97:2347-2353

130. Vilsboll T, Christensen M, Junker AE, Knop FK, Gluud LL (2012) Effects of glucagon-like peptide-1 receptor agonists on weight loss: systematic review and meta-analyses of randomised controlled trials. BMJ 344:d7771

131. Hoofnagle JH, Van Natta ML, Kleiner DE et al (2013) Vitamin E and changes in serum alanine aminotransferase levels in patients with non-alcoholic steatohepatitis. Aliment Pharmacol Ther 38:134-143

132. Bjelakovic G, Nikolova D, Gluud LL, Simonetti RG, Gluud C (2007) Mortality in randomized trials of antioxidant supplements for primary and secondary prevention: systematic review and meta-analysis. JAMA 297:842-857

133. Schurks M, Glynn RJ, Rist PM, Tzourio C, Kurth T (2010) Effects of vitamin $\mathrm{E}$ on stroke subtypes: meta-analysis of randomised controlled trials. BMJ 341:c5702

134. Klein EA, Thompson IM Jr, Tangen CM et al (2011) Vitamin E and the risk of prostate cancer: the Selenium and Vitamin E Cancer Prevention Trial (SELECT). JAMA 306:1549-1556

135. Mudaliar S, Henry RR, Sanyal AJ et al (2013) Efficacy and safety of the farnesoid $\mathrm{X}$ receptor agonist obeticholic acid in patients with type 2 diabetes and nonalcoholic fatty liver disease. Gastroenterology 145:574-582.e571

136. Parker HM, Johnson NA, Burdon CA, Cohn JS, O'Connor HT, George J (2012) Omega-3 supplementation and non-alcoholic fatty liver disease: a systematic review and meta-analysis. J Hepatol 56:944-951

137. Dongiovanni P, Petta S, Mannisto V et al (2015) Statin use and nonalcoholic steatohepatitis in at risk individuals. J Hepatol 63:705-12

138. Valenti L, Fracanzani AL, Dongiovanni $P$ et al (2007) Iron depletion by phlebotomy improves insulin resistance in patients with nonalcoholic fatty liver disease and hyperferritinemia: evidence from a case-control study. Am J Gastroenterol 102:1251-1258

139. Nobili V, Alisi A, Raponi M (2009) Pediatric non-alcoholic fatty liver disease: preventive and therapeutic value of lifestyle intervention. World J Gastroenterol 15:6017-6022

140. Mitchel EB, Lavine JE (2014) Review article: the management of paediatric nonalcoholic fatty liver disease. Aliment Pharmacol Ther 40:1155-1170

141. Feldstein AE, Charatcharoenwitthaya P, Treeprasertsuk S, Benson JT, Enders FB, Angulo P (2009) The natural history of nonalcoholic fatty liver disease in children: a follow-up study for up to 20 years. Gut $58: 1538-1544$

142. Schauer PR, Bhatt DL, Kirwan JP et al (2014) Bariatric surgery versus intensive medical therapy for diabetes-3-year outcomes. N Engl J Med 370:2002-2013

143. Caiazzo R, Lassailly G, Leteurtre E et al (2014) Roux-en-Y gastric bypass versus adjustable gastric banding to reduce nonalcoholic fatty liver disease: a 5-year controlled longitudinal study. Ann Surg 260:893-898, discussion 898-899

144. Lassailly G, Caiazzo R, Buob D et al (2015) Bariatric surgery reduces features of non-alcoholic steatohepatitis in morbidly obese patients. Gastroenterology 149:377-388

145. Charlton MR, Burns JM, Pedersen RA, Watt KD, Heimbach JK, Dierkhising RA (2011) Frequency and outcomes of liver transplantation for nonalcoholic steatohepatitis in the United States. Gastroenterology 141:1249-1253 
146. Wang X, Li J, Riaz DR, Shi G, Liu C, Dai Y (2014) Outcomes of liver transplantation for nonalcoholic steatohepatitis: a systematic review and meta-analysis. Clin Gastroenterol Hepatol 12:394 402, e391

147. Heuer M, Kaiser GM, Kahraman A et al (2012) Liver transplantation in nonalcoholic steatohepatitis is associated with high mortality and post-transplant complications: a single-center experience. Digestion 86:107-113

148. Sebagh M, Samuel D, Antonini TM et al (2012) Twenty-year protocol liver biopsies: invasive but useful for the management of liver recipients. J Hepatol 56:840-847 